\title{
RAFAEL CABRERA MARTÍNEZ: UN DIAMANTE EN EL SILENCIO
}

\section{RAFAEL CABRERA MARTÍNEZ: A DIAMOND IN THE SILENCE}

\author{
Marilín Arias Estrada* \\ Susell Gómez González**
}

RESUMEN

La presente investigación se titula "Rafael Cabrera Martínez: un diamante en el silencio", como lo bautizara el insigne músico cubano, Gonzalo Roig. Esta se desarrolló en la ciudad de Bayamo, de la provincia Granma, con el objetivo de valorar el aporte sociocultural de la figura de Rafael Cabrera para la cultura de Bayamo en el periodo de 1913-1964. La misma tuvo su comienzo en el mes de septiembre de 2010 y su culminación a mediados del mes de mayo de 2011.

PALABRAS CLAVE: CUBA * RAFAEL CABRERA MARTÍNEZ * MÚSICA TRADICIONAL * ORQUESTA * FOLKLORE

ABSTRACT

The title given to this research is "Rafael Cabrera Martínez: a diamond in the silence" as he was called by the outstanding cuban musician Gonzalo Roig. The survey was carried out in Bayamo, Granma province from September 2010 to May 2011. Its main objective is to value the sociocultural grants of Rafael Cabrera for the culture of Bayamo in the period of 1913-1964.

KEYWORDS: CUBA * RAFAEL CABRERA MARTÍNEZ * TRADITIONAL MUSIC * ORCHESTRA * FOLKLORE

Centro Provincial de Patrimonio de Bayamo, Granma, Cuba.

** Facultad de Ciencias Sociales y Humanísticas de la Universidad de Granma, Cuba.

sgomeg@udg.co.cu 


\section{INTRODUCCIÓN}

La historia de la música cubana es un vasto, intrigante y dinámico proceso. Esta exhibe claramente dos caras de una misma moneda: una formada por elementos folklóricos y formas de expresión populares (que se transforman luego en comerciales) y otra, más abstracta y compleja, dentro de la cual algunos compositores cubanos han recorrido la difícil ruta de la música de arte.

Esta última forma o manera, llamada también música clásica, erudita, culta, seria 0 música de concierto, es la menos reconocida en el contexto nacional. Por su falta de exposición y su innata complejidad es posible que en algunos momentos sea ignorada por los propios cubanos, ávidos amantes de la música popular. Como usualmente ocurre en los países que poseen un rico $y$ variado folklore -los cuales, consecuentemente, son voraces productores de canciones populares y de música bailable- la música popular cubana, de muchas maneras $y$ por caminos distintos, ha opacado en gran medida a la música de concierto.

Las primeras composiciones realmente creadas en suelo cubano, como las de Esteban Salas (1725-1803) o de Juan París (1759-1845), son de carácter litúrgico y vocal, a las que se añaden algunos ejemplos de música sinfónica $y$ de cámara. Hay que esperar hasta los albores del siglo XIX para encontrar finalmente, las primeras expresiones de una música que suena diferente a los modelos europeos, referido a los aspectos rítmicos. De la contradanza "San Pascual Bailón" (anónima, 1803) a las contradanzas de Manuel Saumell (1817-1870), se encuentran los primeros acentos, a veces exquisitos, de una música verdaderamente cubana $y$ un modo de sonar realmente autóctono.

Al final del siglo XVIII, esta mezcla musical hispano-africana produce una música bailable de poderosas raíces populares que dentro de la órbita social secular, lentamente desplaza a las danzas europeas que habían constituido hasta entonces el entretenimiento fundamental de la nueva y emergente burguesía criolla. El siglo XIX es testigo de la rápida evolución de esa música danzable rítmicamente diferente de los modelos europeos, la cual ejerce una influencia decisiva en las sofisticadas obras de piano de Saumell y de Ignacio Cervantes (1847-1905), así como, en la música fuertemente romántica de Nicolás Ruiz Espadero (1832-1890). Es también durante este siglo que Cuba produce sus primeros instrumentistas de renombre internacional, del pianista José Manuel ("Lico") Jiménez (1855-1917) y de la pianista y compositora Cecilia Aritzi (1856-1930), a los violinistas Claudio José Domingo Brindis de Salas (1852-1911) y José White (1836-1912).

Deben mencionarse dos compositores quienes, aunque primordialmente actuaron dentro de las fronteras de la música popular y comercial, se aventuraron a crear obras musicales de mayor envergadura y por tanto, ocasionalmente, se adentraron en el campo de la música cubana clásica. Fueron ellos Gonzalo Roig (1890-1970), cuya opereta cubana "Cecilia Valdés" (1932) y "Quiéreme mucho" (1911) han circunnavegado el globo y Ernesto Lecuona (1895-1963), con sus importantes obras de teatro lírico, creando toda una colección de zarzuelas cubanas mundialmente famosas.

Es dentro del marco del siglo $\mathrm{xx}$, que la música de concierto cubana se desarrolló como una de las contribuciones importantes a la historia de Cuba. Los dos primeros compositores cubanos de música de arte que abrazaron las técnicas contemporáneas (en este caso, la música de Stravinsky y de Bartók) fueron Amadeo Roldán (1900-1939) y Alejandro García Caturla (1906-1940), cuyas ricas y atrevidas paletas armónicas, su uso de las grandes formas sinfónicas y su magnética manipulación de las fuerzas orquestales, lograron situar por vez primera a la música cubana dentro de la música contemporánea universal.

Del binomio Roldán-Caturla al presente, la música culta cubana ha continuado creciendo en poder e imaginación, despertando un creciente respeto y admiración internacional. Un valioso $y$ variado grupo joven de compositores cubanos de música de concierto continúan la tarea de expandir la dimensión y el alcance de este tipo de música. Hay que mencionar a Leo Brouwer (nacido en 1939), Alfredo Diez Nieto (nacido en 1918), cuyas composiciones incluyen 
obras sinfónicas, música de cámara y obras vocales; a Carlos Fariñas (nacido en 1934), con sus poderosas y bien realizadas composiciones orquestales; a Roberto Valera (nacido en 1938), creador de excelentes obras corales y a Juan Piñera (nacido en 1950), autor de importantes obras para piano.

Este fenómeno de la música no es exclusivo de la capital cubana, en la ciudad de Bayamo, el tratamiento a este tema resulta relevante, pues han existido significativos músicos que representan periodos de desarrollo de la misma, tal es el caso de Rafael Cabrera Martínez, quien fue director por más de 50 años de la Banda Municipal de Concierto y continuador de una tradición musical legada de su padre Manuel Muñoz Cedeño.

\section{METODOLOGÍA}

Teniendo en cuenta lo antes expuesto, se realiza la presente investigación: "Rafael Cabrera Martínez: un diamante en el silencio", como lo bautizara el insigne músico cubano, Gonzalo Roig, al finalizar su visita a Bayamo, en la cual conoce y disfruta de esta creación.

El escaso reconocimiento y promoción que hoy existe del aporte de este músico a la cultura bayamesa, a partir de sus contribuciones como fundador y director de la Banda Municipal de Concierto, compositor de más de 300 obras musicales en varios géneros, muchas de las cuales se mantienen inéditas. Unido a su labor de maestro de generaciones de músicos y su trayectoria, denotaron el punto de partida para la realización de la misma.

Como problema de investigación se planteó la siguiente interrogante: ¿cuál es el aporte sociocultural de la figura de Rafael Cabrera Martínez para la cultura bayamesa, en el período de 1913-1964?, por lo cual se formuló como objetivo general: valorar el aporte sociocultural de la figura de Rafael Cabrera Martínez para la cultura bayamesa, en el período de 1913-1964.

Se escogió este período de tiempo, precisamente porque es en el que florece en todas las esferas el quehacer de Rafael Cabrera y es en 1913, cuando se instituye la Banda Municipal de Concierto, continuidad de la orquesta fundada en 1868 por su padre Manuel Muñoz.
Para el análisis de su aporte se partió de entrevistas sucesivas, apelando a fotografías, materiales de consulta $y$ datos biográficos. Se empleó además el testimonio de personas que lo conocieron tales como familiares, amigos, compañeros, así como, la utilización de documentos históricos que describieron el contexto de su desarrollo.

Del mismo modo, se encontraron algunos objetos y partituras vagando por distintas instituciones y guardados en la casa de Yolanda Aguilera Iglesias, su albacea, esperando algún evento de ocasión para ser mostrados. Se han realizado pocas investigaciones referidas a él, tal es el caso de una exposición que se realiza en su honor como resultado de una investigación de una estudiante de Museología en el año 1999, en el museo provincial y una compilación de su obra musical por la antes mencionada Yolanda Iglesias, siendo argumentaciones parcializadas, poco concretas y muy efímeras, que sirven de antecedentes a esta investigación.

Es por ello que se considera necesario realizar este estudio, basándose en lo que representa Rafael Cabrera Martínez para el panorama musical y lo que aporta a la cultura bayamesa, deviniendo en urgente estudio desde una mirada integral que propicie el acercamiento $y$ distinción que merece por su labor como músico, patriota, pedagogo y continuador de una magistral carrera en la formación y desarrollo de la música de concierto en Bayamo.

\section{RAFAEL CABRERA MARTÍNEZ: SU APORTE SOCIOCULTURAL A LA CULTURA BAYAMESA}

\section{APUNTES IMPORTANTES DE LA VIDA DE RAFAEL CABRERA MARTÍNEZ}

El conflicto bélico constante entre cubanos y españoles, el tronar de los fusiles y cañones en sus cercanías, como los combates de Jucaibama, El Dátil, El Guanábano, Babiney, Las Mangas y Caureje, unidos a la compleja circunstancia como la ruina de la ciudad de Bayamo y el persistente olor a madera quemada de aquel hecho bravío del 12 de enero en 1869, nació Rafael, hijo del músico Manuel Muñoz Cedeño y Manuela Cabrera Martínez, el 9 de noviembre de 1872 . Al ser un bastardo de 
una relación extramatrimonial llevó los apellidos de su madre.

Una casita modesta, situada en la calle Plaza del Himno, nro.8, entre José Joaquín Palma y Padre Batista, lo cobijó al venir al mundo. Por cuestiones de enfermedad, su mamá fallece y quien cría a Cabrera desde muy temprana edad es Juana Jerez, la esposa oficial de Muñoz.

Desde su niñez, se aprecia un período de formación musical, a partir de la influencia que ejercen su padre y sus hermanos, todos músicos. A la edad de 6 años recibió instrucciones musicales de su padre, a quien le cupo la gloria de instrumentar $y$ tocar por primera el Himno Nacional de Cuba, asimilando conocimientos importantes que lo conllevarían a afianzarse, en el futuro, como un músico de bases muy sólidas. A los 10 años, ya era apto para interpretar el instrumento seleccionado: el clarinete, cuando fue capaz de suplir la ausencia de un músico en la orquesta de su padre. Para los 15 años, escribe su primera obra, una danza, la cual fue incorporada al repertorio de esta con gran aceptación.

Por los avances mostrados por el discípulo, su padre le dio como primer regalo 20 monedas de diferentes valores, que Rafael y posteriormente, sus hijas Aída y Dulce María conservaron hasta el año 1998, cuando deciden donarlas al Museo de la ciudad, constituyendo hoy uno de sus fondos.

Desde esa fecha nunca dejó de tocar en la orquesta de su padre, privilegiado luego con infinidad de obras de relevantes méritos: un capricho sinfónico, polkas, valses, canciones, baladas, danzas, danzones, pasodobles, himnos, marchas militares, de procesión y fúnebres, entre otros. Desde su adolescencia, pudo ver a un padre preocupado por la educación de sus hijos y no solo los del matrimonio, sino de todos los que tenía dentro y fuera del seno familiar.

Compositor, músico y arreglista quien, al fallecimiento de su padre, organizó su propia banda. En las postrimerías de la guerra de independencia del 95, se marchó al Campo Insurrecto, donde fue soldado y llegó al grado de capitán. Fue capaz de incorporar la música de banda en el frente de batalla, siendo integrante de la Banda Mambisa; de esta forma, destacó en todo momento, el germen de defender su identidad y la libertad de Cuba.

Después de terminada la guerra del 95, desempeña el oficio de barbero, dio clases de música en la cochera de su casa y se entrega por completo a la reorganización de la Banda de Música, logra esto en el año 1913, desde ese momento su vida es entregada a la música por entero, tanto a la interpretación como a la creación. El estreno de esta banda fue el 20 de mayo de ese año, bajo su dirección, manteniendo la misma hasta arribar a los 85 años de edad.

Ocupó una posición social importante dentro de la concejalía de cultura de aquella época. El hecho de ser director de la Banda le concedía por derecho ser concejal. Por lo que respecto a otros músicos, tenía una posición más holgada desde el punto de vista salarial, de distinción social, aunque decir músico de esa institución es ya tener una posición importante, por la obra que tiene que hacer en la sociedad, por ser esta quien forma a las nuevas generaciones $y$ al pueblo en el gusto por la buena música, sea nacional o internacional.

Cabrera, típico bayamés que cursó los umbrales de la historia de manera espontánea, sin proponérselo, sin hacer sonar fanfarrias por sus acciones. De origen humilde, quienes lo conocían concordaban en que su carácter era alegre, conversador, respetuoso y cordial. Tuvo múltiples oficios a lo largo de la vida: maestro de Música, director de banda, barbero, concejal, inspector de timbre, auxiliar del departamento de tesorería municipal y músico. Pero la trascendencia le llegó por este último. A él debemos momentos singulares de esa manifestación en Cuba: la fundación de la Banda Municipal de Concierto, continuidad esta de la orquesta fundada por su padre en 1868 y el arreglo de la marcha del 26 de julio, con la llegada de Fidel a Bayamo, en 1959, entre otras cosas.

Se casó con Mercedes Boza Martínez, con quien tuvo cuatro hijos: Rafael, Radamés, Aída y Dulce María, de los cuales fue maestro, todos con talento musical. Destacándose entre ellos Rafael, fundador y solista de la Orquesta Filarmónica de La Habana, dirigida por el 
maestro Pedro San Juan y luego por el genial cubano Amadeo Roldán, del que fue en ocasiones sustituto.

El resto de sus hijos también tuvieron una labor meritoria, pero en el contexto bayamés, esto se evidencia en Aída y su coro de voces masculinas, el cual mantuvo por mucho tiempo y de buena calidad. La presentación de este en las logias, lo benefició mucho, pues participaba en sus fiestas y demás eventos. Aída tenía amor por el coro y por la música, además se dedicó a enseñar.

Por otro lado, Radamés Cabrera, quien junto a Nerio Gonzáles, Ana María Quesada, René Capote y Eloína Guerra, fundó La Escuela de Música. Fue reconocida la labor de maestros que realizaron, pues por más de dos años trabajaron sin sueldo, pero mantuvieron la escuela. Dulce, la otra hija, se inclinó por esta rama, la que enseñó con mucho fervor. Hay que destacar una gran coincidencia entre estos últimos y es su gran labor como maestros.

Rafael Cabrera se mantuvo como director de Banda por más de 50 años, con un repertorio de más de 145 obras. Reconocido como el Padre de la Música de Concierto en Bayamo. Fue fundador de las Milicias Nacionales Revolucionarias y cada accionar suyo demuestra su amor a la patria. Su vida fue dedicada a la patria, la música, la familia y su Bayamo natal.

En su lecho, agobiado por la enfermedad, pero con su mente lúcida, recibió las atenciones y mimos de sus dos hijas. Dulce quien tiene la música en el corazón y la ternura a flor de labios, así como su hija Aída, profesora de piano.

Cuando muere, el 14 de septiembre de 1967, el pueblo agradecido lo acompaña hasta su morada y delante de la carroza fúnebre iba la Banda de Música, dirigida por su hijo Radamés, tocando la marcha "Hacia el Sepulcro", dejando en el recuerdo de los bayameses, todo un repertorio de valiosas obras.

\section{RAFAEL CABRERA MARTÍNEZ Y LA BANDA MUNICIPAL DE CONCIERTO}

Un lugar de obligada referencia en esta historia, le corresponde al padre de Cabrera, el maestro Manuel Muñoz Cedeño. A pesar de que no tuviera un título académico, contaba con los conocimientos equivalentes a todo lo que en sus días estaba pasando respecto a la música universal y así lo demuestran sus composiciones, fruto de una tradición consolidada generacionalmente, que siguió pasando de padres a hijos hasta llegar a nosotros.

La Banda Municipal de Concierto se fundó en 1868, cuando un grupo de músicos, bajo la dirección de Manuel Muñoz Cedeño, orquestó nuestro Himno Nacional y se interpretaron por primera vez sus notas, en el Tedeum de Corpus Cristi. Para muchos, esta no era más que una simple orquesta; sin embargo, contaba con todos los instrumentos fundamentales para constituir una banda, entre estos el clarinete. Esto se corrobora con el siguiente criterio expresado por uno de los expertos: "respecto a composición, esa pequeña orquesta era el embrión de una banda".

Luego se desintegra, como consecuencia del glorioso e histórico alzamiento de Bayamo, en el que muchos de sus músicos van a la manigua redentora como soldados de la Patria que los necesita. Aquellos mismos músicos junto a otros, que también se habían incorporado al Ejército Mambí, formaron en pleno ejército de la guerra, lo que entonces fue la gloriosa Banda Mambisa, que prestó sus servicios durante toda la contienda y precediendo al aguerrido y heroico ejército cubano.

Aquí viene una especie de eslabón perdido, porque muchos músicos bayameses, sobre todo instrumentistas de viento y percusionistas, se fueron después con la banda de música de Antonio Maceo. Esa banda era una unidad de vanguardia en la tropa y Maceo la cuidaba mucho, porque él decía que si perdía un músico perdía un montón de hombres.

Es importante señalar que cada uno de los integrantes de la banda, desde su condición de músicos al partir hacia la manigua y allí formar parte del Ejército Libertador, creó una sonoridad peculiar, que motivaba e impregnaba fuerza en el campo de batalla a sus tropas.

Al concluir la intervención norteamericana, se desintegra la Banda Mambisa y al constituirse la seudo república, Rafael Cabrera creó su propia orquesta (ver anexo 2), como también 
lo hizo el capitán José Joaquín Batista, quien fuera sobresaliente alumno del maestro Muñoz $y$ fundador de la Banda Mambisa. Durante los diez primeros años de ese siglo, ambas agrupaciones eran independientes $y$ desarrollaban su labor musical en la ciudad.

Es el 13 de mayo de 1913, cuando deciden fusionar sus músicos, formando una banda, considerada la primera "Banda Municipal de Concierto de Bayamo" (ver anexo 5), de la cual fue Cabrera su director. A partir de ese momento, este músico ejerce una labor meritoria, pues supo conducirla a la altura del contexto bayamés. La Banda no solo se convirtió en una institución, sino que fue la continuidad de aquella que fundó Muñoz, pasando desde aquel entonces los más difíciles avatares, con una magnífica cualidad musical: su obra, que lo lleva a la gloria de ser uno de los caudales más ricos de la historia de nuestra música. Los diversos criterios lo demuestran:

Su obra se encamina a partir de trasmitir aquellas cosas que había aprendido del maestro Muñoz. Primero que todo fue un conservador, esto se evidencia con la documentación del Himno Nacional, y de obras como "La Rubia", que gracias al trabajo de Cabrera, al cuidado que tuvo con ellas, se conocen hoy.

Es el fruto de una tradición consolidada, ya que su padre Manuel Muñoz, eminente músico le trasmitió el amor por este arte, lo que hizo posible que con solo 10 años ya formara parte de su orquesta $y$ en plena adolescencia, salen a la luz sus primeras composiciones, destacándose como compositor, arreglista e intérprete de numerosas obras, entre sus habilidades llegó a deleitar al público con la música de violín, piano, clarinete y el saxofón (Puig. Director de la Banda de Bayamo, 2011).

En las elecciones de 1926, los políticos hicieron amplio uso de la Banda para sus campañas políticas. Al respecto uno de los expertos comentó:
El general Luis Milanés, postulado para alcalde por el Partido Conservador, animó la creación de otra banda, la de Bomberos. Ofrecieron muchas cosas materiales a músicos de la Banda Municipal $y$ a otros que buscaron, $y$ fundaron dicha banda, bajo la dirección de Antonio María Batista, que era de ese partido. Esta banda se presentaba también en el parque, donde se produjo la Guerra de chicharrones, un enfrentamiento entre las dos bandas (Entrevista: Guerra, 2011).

A raíz de eso, Cabrera escribió la obra "Fuego fatuo", en la que reflejaba la realidad de esa banda, que no era más que salir de mucho traje, tocar en marcha $y$ caminando, sin ser capaces de tocar en concierto. Otros especialistas afirman que esa guerra generó un cantar muy picaresco en dos versiones que decía:

Un domingo en la retreta, se formó un gran titingó, cuando un chicharrón careta a la Banda traicionó. Manuel Fermín cara de cemento.

Un domingo en la retreta un tilingo se formó, que un chicharrón careta a la Banda le ofendió. Manuel Fermín ponte duro, Manuel Fermín ponte duro (Entrevista: Guerra, 2011).

A mediados del año 30, a la Banda de Bomberos le oficializan la plantilla. El ayuntamiento tiene necesidad de hacerlo, para usarla en todas las campañas políticas. Esa era su verdadera función y no una de índole cultural como creían sus músicos. Por lo que no eran respetados como realmente merecían y se tomaban el derecho de poner o quitar a quienes querían, es decir, que no tenían el reconocimiento y menos como institución cultural. A criterio de uno de los entrevistados:

El único alcalde que le dio un poco de atención fue el moro, Blas Elías, quien le posibilitó un uniforme blanco y otro azul, que todavía se conservan, así como 
algunos instrumentos provenientes de una donación que le hizo a la Banda la compañía suiza la Nestlé, que se conservan uno o dos de esos instrumentos con el sello original de esa donación e incluso se mantienen tocando (Entrevista: Naranjo, 2011).

No obstante, los obstáculos característicos de un gobierno despótico y corrupto donde solo el dinero podía hacer milagros, pudo este músico conjugar su grandiosa obra como artista. Su empeño y dedicación en la banda, benefició al movimiento musical, el cual siguió un ritmo ascendente, tanto en el vigor y lozanía de sus creadores, como la calidad y desinterés de los maestros.

A pesar de no contar Bayamo con una sociedad pro-arte musical, continuó haciendo música, demostrando a través de sus partituras, una parte de su propia historia, que finalmente es una parte de la historia de Cuba. Continuó animando los más variados espectáculos, las películas silentes y el recibimiento de visitas importantes a Bayamo.

Uno de los expertos se refirió a que en la década del 50 se mantuvo muy ligado a la revolución, logrando el contacto continuo en las transmisiones lanzadas desde la Sierra Maestra a través de Radio Rebelde $y$ al escuchar el Himno del 26 de Julio, lo escribió, le hizo una trascripción $y$ un arreglo $y$ precisamente el 2 de enero de 1959 cuando entró Fidel a Bayamo fue capaz de tocar esta marcha por las calles de la ciudad frente al edificio que hoy ocupa el Poder Popular, esto hizo que fuera en Bayamo donde por primera vez se escuchase el Himno 26 de Julio interpretado por una banda (Entrevista: Guerra, 2011).

Con este hecho se pone de manifiesto la continuidad histórica y un paralelo importantísimo, Muñoz orquesta el Himno Nacional y Cabrera lleva el pentagrama de su banda después de haberla escuchado en Radio Rebelde, La marcha del 26 de julio. Muestra la importancia no solo de la obra musical, sino como la figura que dio continuidad a una obra que empieza con el Himno Nacional y de aquella música en función de divertir, de aprender y dar cultura.

En esta etapa, hasta enero de 1959, participó en los más significativos acontecimientos culturales celebrados en Bayamo y realizó de forma sistemática retretas en el parque Central, sede permanente de sus conciertos. En 1924, participó en el concurso de bandas de La Habana, en el que obtuvo marcados reconocimientos y más tarde en las fiestas de Santa Cecilia, patrona de los músicos. La Banda Municipal, bajo la dirección de Cabrera se encargó de educar y formar a nuevos músicos para que un día ocuparan un lugar dentro de la misma. La experiencia y el trabajo diario les permitieron a sus integrantes conducirse en el arduo camino de educandos a maestros.

Esta institución no solo mostraba el gran talento de sus integrantes, sino también hechos cotidianos que se daban en esa realidad, esto se materializa en las famosas coplas, esos cantares heredados de los españoles. Sobre esto, uno de los especialistas expresó en uno de los comentarios:

Había en Bayamo una serie de cantares parte de costumbres españolas llamadas coplas, que se referían a cosas que pasaban en la sociedad, con tono picaresco (Hombres corridos, políticos corruptos, enfrentamiento entre bandas). Ejemplo de esto lo constituye la copla referida a una situación que se dio con el matrimonio de Pepe Sánchez, un político que traicionó a su esposa:

No recuerdas Alta Gracia, muy contenta estabas ese día, que te acostaste con Pepe en la cama de Sofía (Entrevista: Puig, 2011).

Después del triunfo de la Revolución, la Banda continuó dirigida por Cabrera hasta 1964, con posterioridad a su fallecimiento la asumió Nerio González y lo sustituyó Radamés Cabrera (hijo). En 1968, ocupó su dirección Joaquín Muñoz, quien realizó importantes cambios y modificaciones en su universo sonoro. 
No se puede dejar de mencionar que fue idea de Cabrera y de un músico importante, que era dirigente de la cultura en las provincias orientales que se llamó Miguel García, que surgieran los Festivales de Banda. Así fue, se celebraron en Bayamo primero anualmente, luego cada dos años, más adelante cada cinco años, con la participación de bandas de diversas provincias y todo eso gracias a la obra de Cabrera. Sin lugar a dudas, desempeñó este una misión importantísima, dirigida a la conservación y superación de las bandas de todo el país, porque esos festivales equivalían a que los músicos de las bandas se pasaran todo un año preparándose para hacer un excelente debut, demostrando de ese modo sus capacidades y habilidades como músicos.

Fue este músico con sus asombrosas cualidades $y$ aptitudes musicales, quien convirtió a esa Banda en una de las instituciones de mayor prestigio en la localidad, llegando a convertirse en una agrupación de respeto ante los valores artísticos musicales cosechados constantemente, a través de sus obras dignas y representativas de lo más genuino y legítimo del quehacer bayamés.

Cabrera fue un músico que no solo trascendió en la localidad o en la nación cubana, sino también en el ámbito internacional por toda su obra, su capacidad y por la manera de creación musical. En primer lugar, fue un director que formó parte de los formatos musicales de la nación del país. Fue considerado el segundo clarinetista de Cuba por toda su calidad musical, es decir, ocupó un lugar cimero en nuestra cultura $y$ tristemente estos méritos no se reconocen a nivel local.

Por sus cualidades ganó el afecto y la amistad de prestigiosas figuras como es el caso del maestro Gonzalo Roig y Amadeo Roldán, aunque no siguió la línea contemporánea de este último, pues se mantuvo con un estilo propio, conducido a la música tradicional.

La Banda salvó los valores locales, la memoria histórica, sus músicos reafirmaron los valores culturales y nacionales. Cabrera amaba a Bayamo con pasión y por ello desechó ofertas valiosas donde pudo obtener gran cantidad de dinero y brillar más como músico. Su esencia estuvo en haber convertido esa banda en reflejo de la vida musical en Bayamo, de las costumbres, los intereses $y$ las cotidianidades de un pueblo, pues una gran parte de la vida de Bayamo estuvo determinada por el hacer de esta institución cultural.

Es toda una continuidad histórica, quién fue Rafael Cabrera, sino el hijo de Manuel Muñoz, quienes integraron esta banda, sino en gran parte los hijos de aquellos músicos que interpretaron el himno y quienes dieron continuidad a esa banda, sino muchos de los nietos de aquellos músicos inmortales de ayer que hicieron historia. Es entonces que la Banda, esa misma que heredó Cabrera y que supo mantener aún en los momentos más difíciles, quien en los años 60 sufre duros avatares. Así es demostrado a continuación:

En los años sesenta después de una evaluación a la banda, se decide subir el salario a los músicos, para aquel entonces la música popular estaba en una posición importante, es entonces que se le termina dando prioridad a esta $y$ ninguna a la de concierto y eso ocasionó la destrucción de las bandas de música en Cuba, pues allá tenían mejor salario. Se tomó la banda como basurero y todo aquel que no diera en un lugar iba para allá. La banda se quedó con una docena de músicos, y la mitad de su plantilla estaba ocupada por jardineros y barrenderos del parque. Hasta que Joaquín Muñoz Casate consiguió rescatarla y mantenerla.

Para aquel tiempo la banda no interesaba, ni siquiera al Consejo Nacional de Cultura, que las dirigía en esa época, nadie se preocupó por los repertorios, y el de aquí, al no contar con un local, fue a parar a los baños de la actual Casa de la Cultura, donde fueron utilizadas como papel sanitario.

Ante la eminente situación Salvador Alarcón, uno de los alumnos de Cabrera, estando en las fuerzas armadas y basándose 
en los conocimientos trasmitidos por el maestro, buscó la alternativa de preparar arreglistas para bandas. De ahí salieron muchos jóvenes como Carlos Puig, que a petición de Joaquín Muñoz debió seguir la obra de la banda (Entrevista: Fonseca, 2011).

Al ponerse de manifiesto el carácter de Banda y Academia de Música, era necesario aumentar la plantilla de músicos consecuentes, capaces de sobreponerse ante cualquier obstáculo. Muchos se incorporaron sin sueldo, como Carlos Puig, por estar en período de formación como músico, hasta que alcanza su calificación técnica requerida y pasó a ser plantilla fija de la Banda, con una meritoria labor y es por ello que se le dio la tarea de mantener tan hermosa obra.

Los músicos interesados en mantenerla, se dirigieron a La Habana a recolectar instrumentos viejos para reconstruirlos. Luego, es asignado un módulo que trajo un xilófono, un bombo y un bombardino de cierta calidad. Lo interesante está en como estos músicos valiéndose de sus propios medios fueron capaces de seguir con la obra legada por Cabrera, independientemente de ser considerada esta banda, para muchos, como una tercera cosa. Lo verdaderamente importante radica en que esta institución es el ente formador de músicos en su propio espacio de creación, que tiene el poder de hacer cualquier tipo de música, desde la más compleja hasta la popular más sencilla.

La Banda es hoy un centro donde se escribe, se graba y en buena medida, se difunde una parte considerable de la música en la provincia. Por eso más que una institución, hay que mirarla como un complejo cultural, capaz de hacer muchas cosas, donde las nuevas generaciones de músicos van a beber allí. Mantiene el mismo espíritu que cuando en una forma embrionaria, estrenó las notas del Himno o interpretó por primera vez el Himno del 26 de Julio. La Banda mantiene su tradición, hace música para la generación en que vive y trata de proyectarla hacia el futuro. Su repertorio es variado $y$ sugerente, se pueden mencionar los siguientes: Himno del 26 de Julio, Himno
Nacional, Himno Guerrillero, Himno del Miliciano, Son dias de Reyes, Fantasías Cubanas, Los Santos y otros.

Continúa siendo una institución respetada a pesar de todas las vicisitudes que ha sufrido. Los griegos decían que la música es la medicina del alma y tenían razón, porque cuando la gente escucha un concierto, se olvida un poco de los avatares y las cosas por las cuales esta pasando, y eso le sirve para poder seguir adelante después.

Qué dejó Cabrera en sus músicos, sino el empeño por mantener una obra que fue el fruto de una tradición consolidada por todo ese tiempo. El estímulo otorgado en 1983, como Mejor Institución de la Música de Concierto en el país, en el género de bandas, resaltan sus posibilidades artísticas, heredadas de su maestro. Sus hijas se dedicaron a conservar un valioso patrimonio cultural de antiquísimas partituras originales, que aun existen y que se están reconstruyendo y digitalizando para que esa música pueda ser tocada por la Banda como prueba de homenaje a tan relevante figura.

La obra de Cabrera en la Banda, denotó el punto de partida para que posteriormente se crearan las bandas de nuevo tipo, en los distintos municipios, con un repertorio contemporáneo, desde lo más clásico hasta lo más actualizado. Como institución musical más importante del territorio, es considerada además uno de los mayores programas de la revolución. Unido a esto, la creación de las escuelas provinciales de arte, donde a través de fechas alegóricas, se desarrollan actividades, bloques, momentos dedicados a la música de concierto. La Jornada "Rafael Cabrera in memorian", el evento de La Mi Si Fa, son algunos de los eventos, en los que se mantiene viva la música de concierto. Un camino bastante seguro que debe continuarse, para que su legado no muera jamás.

En fin, decir Bayamo es referirnos a una geografía bendecida por los encantos de la naturaleza y una rica tradición folclórica, de pensamientos humanistas, de próceres de la patria, de literatura, de música, que la convirtieron desde sus inicios en una de las plazas culturales y patrióticas más importante de la Nación. 
TRAYECTORIA, VIGENCIA Y TRATAMIENTO A SU FIGURA

Un seguimiento de esta personalidad de la cultura bayamesa, nos sitúa en la segunda villa fundada por Diego Velázquez en la isla, en una etapa en que los sentimientos patrióticos que prosperaban entre los lugareños habían tomado fuerzas y se habían convertido en estallido independentista. Hijo de su época, desde su espacio vivió con intensidad el momento y le hizo aportes significativos, como los que a continuación se presentan. No podemos divorciar las diversas vertientes de su vida: él fue uno solo, sin dobleces ni medianías.

A este hombre se debe una generación de músicos, donde su casa y la propia Banda fueron los escenarios fundamentales para enseñar a muchos, que lo continuaron luego, de ellos Salvador Alarcón Rodríguez (ya fallecido), que fue director de la Banda Militar y que siguió el ejemplo de Cabrera, pues fue capaz de formar en el Ejército a más de 150 músicos, siguiendo las pautas trazadas por este.

Tocaba varios instrumentos y dedicó parte de su tiempo a enseñar a todo aquel que se motivaba por la música, inculcaba a sus pupilos hacia el estudio de la música clásica y les enseñaba a tocar instrumentos de viento (metal y madera), percusión $y$ les exigía el estudio de literaturas que contribuyeran a elevar su cultura general (Entrevista: Puig, 2011).

La virtud de haber sido un gran maestro de generaciones, permitió reconocer a varios de sus alumnos a nivel nacional e internacional. Entre los más aventajados puede señalarse a su hijo Rafael Cabrera Boza, fundador y solista de la Orquesta Filarmónica de La Habana, dirigida por el maestro Pedro San Juan y luego por el músico cubano Amadeo Roldán, del que fue en ocasiones sustituto. Julio Cesar, otro de sus alumnos, participó en un concurso en los EEUU, obteniendo un segundo premio (siendo mulato y cubano), cualidades estas que muchos reprochaban y más en el país sede del certamen, además se destaca Salvador Alarcón, quien fuese director de la Banda Municipal de Conciertos en Bayamo.

Durante el periodo, este hombre supo encontrar los elementos nacionales en las entrañas de su pueblo, la verdadera fuente de inspiración y de modo directo e indirecto, un vehículo de ideas revolucionarias para salir del marasmo del régimen seudorepublicano. Pero más trascendental aún, fue el haber tomado a su cargo a diez niños pobres de la ciudad con aptitudes musicales, impartirles clases de música para que luego egresaran a la Banda como educandos. Esto es muestra de la gran riqueza y calidad humana que tenía este gran hombre.

En ocasiones realizó arreglos a composiciones de artistas de renombre, más tarde incorporaría a cada uno de sus conciertos, una serie de costumbres de su pueblo natal. De él expresó en una ocasión el historiador de la ciudad, Orlando La Calle:

Muchos fueron los dones con los que lo benefició la naturaleza, haciendo de Rafael Cabrera un ser intachable, libre de vanidades $y$ con una cualidad exagerada: la modestia, que en él fue su mayor defecto (Archivo de la Biblioteca Provincial de Bayamo, 1868).

Impartía clases de solfeo, de teoría e instrumento en la cochera de su casa. Mantuvo relaciones profesionales con las monjas, pues al abrir estas una Academia de Música, donde se daba clases de piano y se formaban coros, se interesó en saber respecto a los músicos que se formaban ahí, porque inclusive alumnos que estaban estudiando piano en La Habana venían a examinar en este lugar. Cabrera reconoció la ayuda que las monjas prestaron a la ciudad con los coros, entre estos, el de la Iglesia y el de la Capilla, unido a la calidad con que impartían las clases.

Su instrumento fundamental fue el clarinete, pero incursionó en otros, que sería capaz de enseñar posteriormente a sus educandos. Entre su padre y él existe algo interesante, Manuel Muñoz incursionó en una serie de instrumentos musicales como la guitarra, el chelo, 
el violín (considerado por este como el rey), el clarinete, el piano y su hijo, Cabrera, fue capaz de legar la interpretación de ellos unido a otros. Luego, son los hijos de Cabrera quienes legaron todas estas enseñanzas trasmitidas por el padre, los cuales aprendieron música y tuvieron una base musical importantísima. Lo expuesto a continuación por uno de los entrevistados, así lo demuestra:

Fue profesor en la Escuela de Música de Bayamo (hoy día Centro de Superación para la Cultura), al fallecer la escuela adquiere su nombre. Su prestigio sobrevoló las fronteras locales, dándolo a conocer en el ámbito nacional. Activo creador y promotor cultural, intervino en trascendentes acontecimientos citadinos. En sus hijos y discípulos sembró la semilla recibida de su padre. Muchos de estos mostraron los frutos en el extranjero (Entrevista: Iglesias, 2011).

Siempre formó a sus pupilos bajo la concepción de una Cuba libre e independiente. Fue veterano de la guerra del 95, capaz de ir al campo de batalla, donde fue soldado y llegó al grado de capitán. Sus principios estuvieron a la altura de la revolución y eso lo reflejó su obra en la Banda, cuando llevó a su pentagrama la marcha del 26 de julio. Esto demuestra que cada accionar suyo reflejaba el inmenso amor a su patria. Luego sería fundador de las Milicias Nacionales Revolucionarias, para llevar adelante la gran obra de la Revolución.

A consideración de varios expertos, una de las cosas más importantes de esta personalidad, es su labor de rescatar y conservar la obra de su padre. Los variados criterios así lo muestran.

Se considera que es meritorio el trabajo que desarrolló, pues luego serviría de consulta para los futuros músicos, que pudieran beber de estos conocimientos importantes. Él fue quien colocó la piedra angular del archivo, que las hijas fomentaron con dedicación hasta sus últimos días. Un documento tan singular como la partitura original del Himno Nacional que perteneciera a Muñoz, aportado por Aída y Dulce María al Museo Nacional de la Música. Dejó toda una cantera de músicos forjados, entre los que estuvieron los hermanos violinistas Julio César y Catalino Arjona, que conquistaron merecida fama en los EEUU y otros países; Salvador Alarcón Rodríguez, quien luego asumiría la dirección adjunta de la Banda y sus hijos, los cuales ocuparon una posición importante en la ciudad de Bayamo.

Todos los criterios de los entrevistados, respecto al tratamiento dado a la figura de Rafael Cabrera Martínez, coincidieron en que no ha sido el mejor, pues que actualmente no se tenga conocimiento de esta, en gran parte es el resultado de una inadecuada promoción sobre este hombre, que dedicó parte de su vida aportando a su cultura, la bayamesa:

Cabrera creó y dejó una rica y vastísima obra que hasta ahora no ha tenido la divulgación necesaria. Aún a partir de la década del 90 se instituyó la jornada "Rafael Cabrera in memorian", que hay que destacar que en el 2010 no se realizó, que si bien ayuda a la difusión del quehacer de las bandas, hay muy poco espacio para reflexionar $y$ discutir sobre los aportes del músico bayamés a la música regional y cubana en general.

El tratamiento que se la ha dado a su figura no revela su multifacético quehacer, ni a ese hombre que se consagró de cuerpo y alma para que floreciera la cultura musical del pueblo cubano. No se ha hecho una promoción importante sobre su repertorio y el de otros músicos significativos como Benjamín Muñoz, la familia Gonzáles, los hermanos Pérez, Salvador Alarcón, Luis Alarcón y sus hijos, y el propio Carlos Puig Premión.

No se ha reconocido a nivel estatal con la importancia que merece, no se ha hecho un trabajo adecuado, $y$ muestra de esto lo constituyen los años que hace que en Bayamo se quiere hacer un Museo de la Música, pues sería importante conservar no solo la obra de Cabrera, 
sino también la de otros músicos como Nerio Gonzáles, Radamés Cabrera, Luis González conocido como chichito, Benjamín Muñoz y otros.

Este músico es recordado mediante la jornada "Rafael Cabrera in memorian", los festivales de banda $y$ otros, pero es muy poco para lo que hizo ese hombre. Se considera que en las escuelas de Música ( $y$ en memoria de aquella que llevó tanto tiempo su nombre) dentro de las asignaturas de Historia de la Música cubana y la de Historia Universal, deben aparecer biografías, clases magistrales que ayuden a conservar la música del territorio $y$ figuras como esa.

Independientemente de que quizás este tipo de música no guste a todo el mundo, es meritorio reconocer que en Bayamo, hay una gran afluencia de público a lugares donde se presenta esta, por la tradición de siglos anteriores, pues hay que recordar que en esta ciudad para los siglos XVI y XVII, ya se realizaban tertulias literarias hogareñas, donde estaba presente el piano. Un tipo de música que tiene vigencia desde el punto de vista histórico, cultural y social, pues cuando se escucha te invita a sentirte bien, llena de romanticismo, de amor y sobre todo de patriotismo, pues su mensaje resalta el carácter cubano.

Una obra que sirve de consulta para las personas que tienen cierta habilidad y capacidad para analizarlas en un sentido amplio $y$ para grandes músicos de la Nación, que pueden llegar a conocer de peculiaridades y especificidades de una obra, que a consideración de muchos, estuvo muy bien compuesta. No obstante, no hay que tener dotes musicales para darse cuenta, que estas obras ilustran una parte de Bayamo en torno a representaciones compartidas, tradiciones, historietas, raíces comunes, estilos de vida, motivaciones, actitudes, partes componentes de un pueblo que vivió momentos difíciles como fueron esos años. Sin embargo, se convirtió en punto de partida para que este hombre siguiera creando mediante su labor multifacética. El pueblo se identificó con la música de la Banda, donde no solo se ilustraban esas composiciones, sino a una parte de la historia del pueblo bayamés.

Actualmente su obra no es tocada, pero es trascendental que la Banda Municipal de Concierto este llevando a cabo, una labor de recuperación de esas partituras las cuales se encuentran muy dañadas, para dejar constancia de lo que hizo este gran anfitrión y fiel exponente de la música de concierto en Granma. Sus habilidades llegaron a deleitar al público con su música de violín, piano, clarinete y saxofón. Como hombre se valora a través de su labor de enseñar a otros, una persona correcta, merecedor de su Bayamo natal, pues esta provincia fue $y$ es musical $y$ trovadoresca.

Su relevante actuar también se evidenció en "La Diana mambisa", otra de sus tantas ideas. Esta consistía en un paseo en coche, al amanecer, acompañado por dos o tres músicos que él mismo elegía. La realizaba cada día festivo, fundamentalmente en fechas gloriosas. Esta actividad mantenía viva muchas de las tradiciones de la ciudad, el coche como elemento representativo de estatus, de paseo, de medio de transporte. La serenata muy amena, más bien trovadoresca, el propio nombre hacía homenaje a esa gloriosa mujer que fue la poetiza Diana.

Convirtió su cumpleaños, en un espacio ameno, de intercambio musical, con el trío integrado por Eloína Guerra, Teté y Martha Milanés. Otros músicos también fueron partícipes de ese encuentro que se volvió una costumbre. Cabrera supo aprovechar cada ocasión para trabajar por la música, para que esta saliera del marasmo en que se encontraba en la seudo república. Fue precisamente en uno de esos escenarios donde su buen amigo Sindo Garay, compuso "La mujer bayamesa", mirando a una de las ruinas aun vivientes del incendio bravío de décadas anteriores.

Los viernes festivos iniciaba su presentación con un himno alegórico a José Martí, con un solo de trompeta. Parte de estas memorias nos muestran, asimismo, a un hombre empeñado en que su prole aprendiera música. Insistió siempre en que los chicos conocieran varios instrumentos y tuvo éxito en su propósito. Su labor no solo se enfocó en este sentido, sino 
también se ocupó de todo un variado cúmulo de acciones, para el mejoramiento de la vida cultural de la ciudad.

Quien conozca la historia de Bayamo, quien sepa de los sacrificios y del patriotismo de aquella generación que floreció y fructificó a toda una ciudad, no debe de obviar los aportes de esta figura, que son esencia y autenticidad. El mérito de haber conducido la Banda con tanta eficacia, lo hizo ser parte fundamental de la rica historia de la ciudad de Bayamo. Desarrolló un vasto quehacer cultural, con su repertorio y meritorio aporte a la música de concierto, legado luego para todas las generaciones precedentes. No se pueden ignorar aquellas magníficas cualidades musicales, que lo llevaron a la gloria de ser uno de los caudales más ricos de la historia de nuestra música.

No se podrá hablar, entonces, de la cultura del pueblo bayamés, sin que sea tocada, junto a otras, esta figura de renombre, pues legó un conocimiento general sobre particularidades de valores representativos de nuestra herencia histórica cultural. El papel que puede desempeñar una personalidad en la contribución a la cultura de un pueblo, el diálogo con sus obras en el transcurso de los siglos, son elementos fundamentales para la educación integral de las generaciones presentes.

Su decursar ofrece una clara información de su existencia, que incita el interés por conocer características de la época, porque fue un hombre que tuvo una larga vida, en tres épocas diferentes, pero iguales, en tanto evidencian el accionar de hombres que no se conformaron con un medio atropellador y obstaculizante, sino que con sus obras, con su proceder, forjaron principios independentistas. Toda una obra legada, que reafirma la acumulación de valores, que constituyen parte integral del patrimonio cultural bayamés. Las costumbres y tradiciones heredadas marcan a esta ciudad, con un sentido de pertenencia de las creaciones de grandes hombres, como el aquí abordado.

\section{CONCLUSIONES}

El reto de la presente investigación ha sido traer del pasado a nuestra memoria cultural, la historia del músico bayamés Rafael
Cabrera Martínez, en una apretada síntesis de su vida y obra, desde la cual se logra la valoración del aporte del mismo a la cultura bayamesa. Es por ello que se arriba a las siguientes conclusiones:

1. En la investigación se logró la realización de la historia de vida de Rafael Cabrera Martínez, a partir de la definición de pasos de investigación que permitieron establecer el aporte del mismo a la cultura bayamesa.

2. $\quad$ El aporte de Cabrera a la cultura bayamesa se valora a partir de su trabajo en la Banda Municipal de Concierto en 1913 y como director de la misma por más de 50 años.

3. Se estima además a partir de su desempeño como maestro de varias generaciones de músicos de Bayamo. Formando toda una cantera, entre ellos sus hijos, que legaron una variedad de conocimientos que aún se transmiten de generación en generación.

4. Otro aporte importante fue su labor imprescindible como arreglista, así como, el rescate y conservación de objetos importantes de su progenitor, el arreglo original a la letra del Himno Nacional.

5. En cuanto a vigencia y tratamiento a su figura, en la actualidad no se le da una eficiente promoción a su obra, aunque se realizan los festivales de bandas, en ocasiones actividades que tributan a este y la jornada "Rafael Cabrera in memorian".

6. La cultura musical bayamesa es el resultado de intrincadísimas transculturaciones. Aún en el siglo Xx, constituye un punto de partida para nuevas investigaciones.

7. El vasto quehacer cultural de la ciudad de Bayamo, en especial en el campo musical, la convierte en una de las primeras y más importantes ciudades del país, tanto en acontecimientos históricos como en ser cuna de ilustres personalidades.

\section{BIBLIOGRAFÍA}

Aceves Lozano, Jorge E. Un enfoque metodológico de la historia de vida. México: Ediciones Ciesas, 1996. 
Álvarez Álvarez, Luis y Barreto Argilagos, Gaspar. El arte de investigar el arte. Santiago de Cuba: Editorial Oriente, 2010.

Ardévol, José. Introducción a Cuba. La música. La Habana: Instituto del Libro, 1969.

Céspedes Argote, Onoria y Chávez Pardo, Eduardo. Bayamo síntesis histórica. Bayamo: Editorial José Joaquín Palma, 1989.

Chirico, Magdalena. Los relatos de vida. El retorno a lo biográfico. Editorial América Latina: Buenos Aires, 1992.

Chorens Dotres, Roberto. Seminario de Apreciación e Historia de la Música. La Habana: Juventud Rebelde, s. f.

Cobas Sanz, Mario. "Bayamo y la sociedad filarmónica en el siglo XIX". Ventana Sur 6. Julio- diciembre 2008.

Colectivo de autores. Bayamo en el crisol de la nacionalidad cubana 1. Bayamo: Ediciones Bayamo, 1996.

Colectivo de autores. La historia en la palabra 1. Bayamo-Granma: Editorial Bayamo, 2003.

Colectivo de autores. La historia en la palabra: la historia en las revistas culturales. Bayamo: Ediciones Bayamo, 2005.

Colectivo de autores. La historia en la palabra 5. Formación y desarrollo identitario. Bayamo-Granma: Ediciones Crisol, 2008.

Eli Rodríguez, Victoria y Gómez García, Zoila. Haciendo música cubana. La Habana: Editorial Pueblo y Educación, 2002.

Fernández G., María V. "Orquesta Sinfónica". A propósito de Bayamo. BayamoManzanillo: Ediciones Simiente, 1999.

Fernández Pau, Yarié y Bodón García, Pedro. Algunas consideraciones acerca del proceso histórico de la Banda de Música de Bayamo. Ciudad de Bayamo, 1996.

Giro, Radamés. Diccionario Enciclopédico de la Música Cubana. La Habana: Editorial Letras Cubanas, 2009.

Hernández Sampieri, Roberto. Metodología de la investigación. México: Editorial Mexicana, 2006.

León, Argeliers. Del canto y el tiempo. La Habana: Editorial Pueblo y Educación, 1981.

Linares, María Teresa. La música y el pueblo. La Habana: Editorial Pueblo y Educación, 1974.
Maceo Verdecia, José. Bayamo. Bayamo: Ediciones Bayamo, 2009.

Mari Aguilera, Idelmis. Fuego y acaso. Ediciones Bayamo: Bayamo, 2006.

Moreno, Alejandro. Historias de vida $e$ investigación. 2009.

Naranjo, Aldo Daniel. Contextualización de Bayamo en la Colonia. 2010.

Ortiz, Yoel. "Acento página del ayer". Ventana Sur 1. Octubre 1999.

Orovio, Helio. Diccionario de la Música Cubana. La Habana: Editorial Letras Cubanas, 1981.

Palacios García, Eliseo. Catálogo de Música de Concierto. La Habana: Editorial Instituto Cubano de Música, 1990.

Roig Leuchsnring, Emilio. Historia de la Enmienda Platt. La Habana: Editorial Nacional de Cuba, 1967.

Rodríguez López, Dayami. "Las sociedades de recreo en la cultura bayamesa”. Ventana Sur 4. Enero-diciembre 2007.

Rodríguez Gómez, Gregorio. Metodología de la investigación cualitativa. La Habana: Editorial Félix Varela, 2006.

Riera Hernández, Mario. Bayamo Político 18981956. La Habana: Editorial Propiedad Intelectual, 1957.

Salvador Guerra, Juan. "Una ciudad, una tradición, una banda... Y muchas piedras en el camino". A propósito de Bayamo. 1999.

Saltalamacchia, Homero R. La historia de vida. Reflexiones a partir de una experiencia de investigación. Ediciones Cijup, 1992.

Salazar, Adolfo. La música como proceso histórico de su invención. La Habana: Editorial Arte y Literatura, 1987.

Taylor, S.J. y Bogdan, R. Introducción a los métodos cualitativos de investigación. Buenos Aires: Editorial Paidós, 2002.

Valdés, Carmen. La música que nos rodea. La Habana: Editorial Arte y Literatura, 1979.

PERIÓDICOS

Carbonell Alard, José. La Demajagua 1 (277). s. f. En: <http://www. Lademajagua.co.cu> [consultada el 25 de septiembre de 2010]. 
Garciaporrúa, Jorge. "Cuba: música de concierto". Tabloide: De música y músicos cubanos. Diario Juventud Rebelde. S/f. p. 24.

"Melodía y compás en tiempo abreviado". La Demajagua 860. 24 de mayo de 2008. En: <http://www. Lademajagua.co.cu> [consultada el 25 de septiembre de 2010].

"Proyección tabloide cultural". La Demajagua 4. 11 de enero de 1981. En: <http://www. Lademajagua.co.cu> [consultada el 25 de septiembre de 2010].

"Metodología de la historia de vida". En: <http://www.scribd.com.doc.8290699> [consultado el 25 de octubre de 2010].

\section{ENTREVISTAS}

Fonseca, Ludín (historiador de la ciudad de Bayamo). Evento Crisol de la Nacionalidad Cubana. Bayamo, Cuba. Octubre 2011.
Guerra García, Eloína (amiga y compañera de Cabrera). Ciudad de Bayamo. 26 de mayo de 2011.

Iglesias, Yolanda (albacea de Cabrera). Casa de habitación. 13 de septiembre de 2011.

Naranjo, Aldo (especialista del Museo Provincial de Bayamo, Cuba). Museo Provincial Manuel Muñoz Cedeño. 12 de febrero de 2011.

Puig Premión, Carlos (director de banda en una presentación en Plaza del Himno de Bayamo, Cuba y músico de la Banda Municipal de Concierto). Bayamo. 2011.

OTROS

Archivo de la Biblioteca Provincial de Bayamo. Materiales donados por Orlando La Calle. 1868.

Fecha de ingreso: 07/11/2011 Fecha de aprobación: 01/06/2012 


\section{ANEXOS}

ANEXO 1

PRIMERA ORQUESTA TÍPICA DE LA CIUDAD DE BAYAMO

\begin{tabular}{cc}
\hline MÚSICO & INSTRUMENTO \\
\hline Manuel Muñoz Cedeño & Violín \\
Pedro Muñoz Jerez & Violín \\
Juan Ramírez & Violín \\
Manuel Muñoz Jerez & Clarinete \\
Joaquín Fonseca & Clarinete \\
Jesús Echevarría & Clarinete \\
José Caridad Cedeño & Cornetín \\
Miguel Aguilera & Trombón \\
Juan Aguilera & Trombón \\
Francisco Cedeño & Bombardino \\
Francisco María Tamayo & Figle \\
José María Aguilera & Contrabajo \\
\hline
\end{tabular}

ANEXO 2

ESTRUCTURA DE LA ORQUESTA CREADA POR EL MAESTRO CABRERA

\begin{tabular}{cc}
\hline MÚSICO & INSTRUMENTO \\
\hline Rafael Cabrera Martínez & Clarinete (primero) \\
Joaquín Casate & Contrabajo \\
Sipriano Curujal & Cornetín \\
Pepe Muñoz Ginarte & Trombón \\
Pedro Céspedes & Trombón \\
Nene Muñoz Ginarte & Trombón \\
Lorenzo Cabrera & Bombardino \\
José Arjona & Bombardino \\
Manuel Céspedes & Clarinete \\
Pedro Muñoz Ginarte & Violín \\
Pedro Tablada Morales & Flige \\
José Caridad Aguilera & Timbales \\
AmbelioTamayo & Güiro \\
\hline
\end{tabular}


ANEXO 3

GUÍA DE ENTREVISTA

Objetivo: Obtener información sobre aspectos importantes relacionados con la vida y obra de Rafael Cabrera Martínez

Objeto: Los expertos: Carlos Puig Premión, Director de la Banda Municipal de Bayamo y músico. Orlando Quezada Arévalo, músico, coreógrafo e integrante de la Banda. Gertrudis Altunaga Quezada, especialista en museología.

Tipología: En profundidad

Cuestiones de indagación: Profesionales

\section{Guía temática}

$\diamond \quad$ Formación académica: escuelas, profesores memorables, amistades influyentes y aspectos culturales en su marco de formación.

$\diamond \quad$ Formación cultural: sus primeros intereses como músico, instituciones culturales que hayan tenido cierta influencia sobre él.

$\diamond \quad$ Inicios de su labor como músico y otras cuestiones. Descripción de la institución fundamental, en la cual se vio inmerso. Colegas.

$\diamond \quad$ Trayectoria posterior.

$\diamond \quad$ Estilo, política cultural e intercambio con el medio.

$\diamond \quad$ Consideraciones generales respecto a la realización del estudio. 
ANEXO 4

BANDA MUNICIPAL DE BAYAMO EN EL AÑO 1913

\begin{tabular}{cc}
\hline MÚSICO & INSTRUMENTO \\
\hline Rafael Cabrera Martínez & Clarinete (primero) \\
José Joaquín Batista & Bajo \\
Joaquín Baris & Bajo \\
Manuel Rivero & Bombardino \\
Lorenzo Cabrera & Saxo barítono \\
Manuel Fonseca & Cornetín \\
Mariano Vázquez & Cornetín \\
Manuel Cabrera & Cornetín \\
Ricardo Cabrera & Cornetín \\
Antonio Estrada & Trombón (primero) \\
Joaquín Sotero & Trombón \\
Feliciano Escobedo & Flauta \\
Joaquín Casate & Clarinete \\
Rafael Licea & Clarinete \\
Paco Cedeño & Bajo \\
Manuel Muñoz & Requinto \\
Ricardo Vázquez & Platillo \\
Andrés Lolín & \\
\hline
\end{tabular}

ANEXO 5

CARACTERIZACIÓN DE ALGUNAS DE SUS OBRAS

Título: Elena la Cumbanchera

Autor: Rafael Cabrera Martínez

Género: Guaracha Son

14 particellas

$\diamond \quad$ Título: Himno a Maceo

Autor: Letra de Bonifacio Byrne (como una poesía hecha himno por Rafael Cabrera, el cual le pone la música y la orquesta)

Género: Himno

Fecha: 7 de diciembre de 1907

22 particellas

$\diamond \quad$ Título: Fuego Fatuo

Autor: Rafael Cabrera Martínez

Género: Polka

Dedicado especialmente a la Banda de Bomberos por su poco tiempo de acción 
$\diamond \quad$ Título: En lo Ignoto

Autor: Rafael Cabrera Martínez y Benjamín Muñoz

Género: Vals

Fecha: 1895

Dedicado a su padre Manuel Muñoz Cedeño, Orquestador del Himno Nacional

$\diamond \quad$ Título: Mis 84 años

Autor: Rafael Cabrera Martínez

Género: Danzón

Lo dedica así mismo por cumplir sus 84 años y sentir el dolor de la enfermedad, es la última canción que escribe y orquesta.

$\diamond \quad$ Título: Lejos de Hogar

Autor: Rafael Cabrera Martínez

Género: Capricho Sinfónico

Fecha: 22 de noviembre de 1915

Dedicado a su hijo Rafael Cabrera Boza cuando fue a estudiar y trabajar para La Habana con posible salida del país.

Como parte de sus fondos también se encuentran los siguientes:

$\diamond \quad$ Valses:

Lirio de Verano, Espejismo, Isabel, El último adiós, Dulce María, Aída, La ingratitud de Zelmira, Tarde de Valses, Rosario, Inés, Celia, entre otros.

$\diamond \quad$ Danzas:

Vámonos para el pueblo en Semana Santa, Dame de tus labios un beso.

Paso doble: Los exploradores, El reajuste, Ay Rosiña.

$\diamond \quad$ Danzones:

Escalas y arpegios, Carne de macho, El guiñapo, 1911, 1912, 1914, Ay Ricardo tú tienes la culpa, Brisas Marinas, En la rivera de Bayamo, Añoranzas juveniles, Mi hombre, Mi longuita, Tarde de primavera, etc.

$\diamond \quad$ Himnos:

Himno del 24 de febrero, Himno Amazónico, Himno del Orfeón Martiano, entre otros.

$\diamond \quad$ Marcha de procesión:

Divina Pastora, Mi ofrenda, Mater Inmaculada, Nostalgia al cielo, Bendita sea tu pureza, Ave María, Romanza a la Virgen, entre otras.

$\diamond \quad$ Marchas fúnebre:

Hacia el sepulcro, Corona de siempre vivas, Misa de difuntos, Recuerdo a Lino Boza. 
ANEXO 6

RELACIÓN DE OBRAS COMO PARTE DE LOS FONDOS DEL MÚSICO

\begin{tabular}{|c|c|c|c|}
\hline NRO. & OBRA & GÉNERO & AÑO \\
\hline 1 & Bayamo & Marcha & \\
\hline 2 & Celia & Danzón & \\
\hline 3 & Espejismo & Vals & \\
\hline 4 & Gratitud de corazón & Vals & \\
\hline 5 & Sobre la tumba & Marcha & \\
\hline 6 & Himno Masónico a Bayamo & Himno & $24 / 04 / 1917$ \\
\hline 7 & Meditación & Vals & \\
\hline 8 & Lirio de Verano & Vals & \\
\hline 9 & Divina Pastora & Marcha & 1929 \\
\hline 10 & Recuerdo a Lino Boza & Marcha & \\
\hline 11 & Santa Cecilia & Marcha de Procesión & 1924 \\
\hline 12 & Corona de siempre vivas & Marcha & \\
\hline 13 & Canto Mambí & Marcha & \\
\hline 14 & Nenita & Vals & \\
\hline 15 & Dulce María & Danzón & 1930 \\
\hline 16 & Mi ofrenda & Marcha & \\
\hline 17 & En la rivera de Bayamo & Capricho & \\
\hline 18 & Obsesión & Vals & 1920 \\
\hline 19 & Fuego fatuo & Polka & 1938 \\
\hline 20 & En lo ignoto & Vals & 1895 \\
\hline 21 & Escalas y arpegios & Danzón & 1920 \\
\hline 22 & Los Boys Scouts & Pasodoble & 1926 \\
\hline 23 & Melodía soñada & Bolero & 1942 \\
\hline 24 & 24 de febrero, Comandante Santiesteban & Danzón & 1957 \\
\hline 25 & Elena la cumbanchera & Guaracha son & 1959 \\
\hline 26 & Romanza a la Virgen & Marcha & 1920 \\
\hline
\end{tabular}




\begin{tabular}{|c|c|c|c|}
\hline NRO. & OBRA & GÉNERO & AÑO \\
\hline 27 & Hacia el sepulcro & Marcha & 1934 \\
\hline 28 & Misa de difuntos & Marcha & \\
\hline 29 & Mis 84 años & Danzón & 1957 \\
\hline 30 & Alegre (solo partichela) & Marcha & 1907 \\
\hline 31 & Triste revelación & Mazurca & \\
\hline 32 & Himno Orfeón Martiano & Himno & 1953 \\
\hline 33 & Lejos del hogar & Capricho Sinfónico & $22 / 11 / 1915$ \\
\hline 34 & Añoranzas juveniles & Danzón & 1957 \\
\hline 35 & Nostalgia al cielo & Marcha & 1920 \\
\hline 36 & Obertura a Eleonor & & 1927 \\
\hline 37 & Bendita sea tu pureza & Marcha & 1917 \\
\hline 38 & Stella & Danzón & \\
\hline 39 & Ave María & & \\
\hline 40 & La sirena & Vals & \\
\hline 41 & Tarde de primavera & Vals & \\
\hline 42 & 24 de febrero & Marcha & \\
\hline 43 & Sol de Triana & Pasodoble & \\
\hline 44 & El reajuste & & \\
\hline 45 & Ay Rosiña & Pasodoble & \\
\hline 46 & Mater Inmaculada & Marcha & \\
\hline 47 & Corpus Christi & Marcha de Procesión & 1917 \\
\hline 48 & Himno escolar "Beso a la patria" & Himno & \\
\hline 49 & Diana Agramonte & Danzón & \\
\hline 50 & La alegría de la muerta & Jota & \\
\hline 51 & Rumbo a Bayamo & Balada & \\
\hline
\end{tabular}


